\title{
Evaluation of the effect of optimal fit criteria on the compressive strength of open mortise and tenon corner joints
}

\author{
László Elek $^{1} \cdot$ Zsolt Kovács $^{1} \cdot$ Levente Csóka $^{1} \cdot$ Charu Agarwal $^{1}$
}

Received: 29 April 2019 / Published online: 19 February 2020

(c) The Author(s) 2020

\begin{abstract}
The study examines the degree of deviation from the nominal size of the produced open full-width mortise and tenon joint elements for their optimal pairing based on the measured thickness and gap width data. The characteristics of the measuring devices used were analysed by the repeatability and reproducibility test. The compressive strength of the single-glued joints (where only the surfaces of the tenon were glued) and double-glued joints (where the surfaces of both the mortise and tenon elements were glued) for various joint fit categories was also determined. It was found that despite the huge number of produced test specimens and their measurements, the joint fits could be maintained with the milling machine and tools. The thickness of the joint could be characterized by measuring the data at the centre of the tenon, whereas the gap width of the mortise could be characterized by measuring the data on the side of the tool leaving the wood. The double-glued joints showed higher breaking force and displacement values as compared to the single-glued joints. The joints were found to be the strongest at a tight fit of $0.1 \mathrm{~mm}$.
\end{abstract}

\section{Introduction}

Timber is one of the oldest, most popular and versatile natural materials known to mankind. Most of the scientific knowledge of the structural use of timber has accumulated over centuries, but the inhomogeneity and anisotropy of timber have left many unexplored areas still to be clarified (Merk et al. 2014; Ramage et al. 2017). For most of the manufacturing and processing operations, many aspects including wood inhomogeneity, changes in environmental conditions and machining parameters are of immense significance. The strength, rigidity and stability of timber are essential factors to be considered for the safe and economical design of the structural elements (Eckelman and Suddarth 1969; Imirzi et al. 2015; Jivkov and Marinova 2006). For furniture and other timber constructions, the quality and durability of the various glued structural joints used are significantly

Electronic supplementary material The online version of this article (https://doi.org/10.1007/s00107-020-01509-w) contains supplementary material, which is available to authorized users.

Charu Agarwal

charu.agarwal3@gmail.com

1 Institute of Wood Based Products and Technologies, University of Sopron, Sopron 9400, Hungary influenced by the structural fit of the comprising elements in addition to several other factors (Prekrat and Smardzewski 2010). Joints are the weakest points of the wooden structures and usually the points of failure, thus it is crucial to take into account the tolerances and fit systems in joints in design and production (Eckelman 2003).

The machining accuracy and the moisture content of the wooden specimens have a profound impact on the quality of the joints produced (Tankut and Tankut 2011). By choosing and maintaining the appropriate tolerances, it is possible to produce the required joint elements that ultimately reduce both the scrap and the customer complaints. The practices on opting for the joint fits may vary from place-to-place with no general guidelines to follow; there may be instances where the loose or fixed joint fits are preferred to the tight fits and vice versa. However, the joint fit is essentially determined by the type of the product to be manufactured, in addition to the type of wood, the moisture content of the raw material, the type of adhesive and the type of machining used (Altun et al. 2010; Ratnasingam and Ioras 2013; Wilczyński and Warmbier 2003).

In the timber industry, the dimensions of the manufactured products in the series production line are never exactly identical, even with the most accurate settings, technological parameters and the best quality of raw material. In practice, variations in the external or internal factors such as machine 
accuracy, rotating machine elements, vibrations, accuracy of the guiding component to be machined, material characteristics and tool characteristics may occur in a number of ways (Kasal et al. 2016; Ratnasingam et al. 2010). The regulation task involves the minimization of the errors caused by variations in these factors and stabilization of the production process. A well-regulated production process ensures that, subject to predetermined technological parameters, comprehensive statistical methods are used to determine the theoretically acceptable tolerances. The better the regulation of a production process, the more positive the outcome of quality assurance methods supported by statistical methods, such as reduction in the scrap, fewer post-production and error corrections, increasing customer satisfaction, etc. can be achieved (Kovacs 2017).

The measurement itself is a process, which is influenced by the combined effect of a number of input factors such as the measuring instrument, tester/operator, manufactured product, environment and the method (Viswanathan 2005). It is indispensable to examine the characteristics of the measuring instrument to be used for data measurement (Hajdarević and Martinović 2014). Once the necessary process parameters are determined and the measurement method is confirmed, a measuring instrument must be selected for the trial. It is of utmost importance to verify that an appropriate measurement system has been applied to evaluate the parameters to be tested. The suitability of the manufactured product, the sequence of the process operations, need for process improvement, etc. depend on the outcome of the in-depth analysis of the measurement data (Erdil et al. 2005).

The differences in the measurement data arise due to several factors. The manufactured products may differ in physical dimensions due to variation in machining. The tester may make random measurement errors originating from individual-related or method-related sources, thus affecting the repeatability of the data (Viswanathan 2005). The skilfulness, the attentiveness and the reliability of the operators may be different, which determines the reproducibility of the data. The lesser the variation in the measurement data due to the measurement system, the more accurate the manufacturing process. An ideal measurement system causes minimum possible variation in the measurement data.

After reviewing the types of wooden joints with their usual dimensions and the timber species commonly used by the furniture industry, the open full-width mortise and tenon joint was chosen for the study as it is commonly used in practical life and can be produced using basic woodworking tools and measuring instruments (Kasal et al. 2016). Amongst the various hardwoods, the European ash wood was selected for the production of the joint elements. The present study aimed to examine the degree of deviation from the nominal size of the produced mortise and tenon joints as well as recommend the perfect pairing of the joint elements taking into account the direction of machining, based on the measurement data. The characteristics of the measuring instruments were analysed by the repeatability and reproducibility $(\mathrm{R} \& \mathrm{R})$ test. The compressive strength of the glued joints for different joint fit categories was used as a tool for validating the concept of optimal pairing of the wooden joint elements. Finally, the optimal joint fit of the mortise and tenon joint was determined.

\section{Materials and methods}

\subsection{Materials}

\subsubsection{Materials}

High-quality European ash wood (Fraxinus excelsior) was purchased in the form of $1035 \times 65 \times 25 \mathrm{~mm}$ size cabinets from IKEA Industry Ltd., Hungary. The moisture content of ash wood was checked under laboratory conditions in accordance with the standard ASTM D4442 "Standard test methods for direct moisture content measurement of wood and wood-based materials". The wood specimens were dried in the oven at $103 \pm 2{ }^{\circ} \mathrm{C}$ to constant weight and the moisture content was found to be $10 \%$. For the gluing of the joint elements, a Technobond 3000 D3 waterproof adhesive, was procured from Szolvegy Ltd., Hungary. The adhesive was a polyvinyl acetate dispersion with the following specifications: viscosity: $9.0 \pm 2.0$ Pas, density: $1.08 \mathrm{~g} / \mathrm{cm}^{3}, \mathrm{pH}: 3.0 \pm 0.4$, minimum film forming temperature: $5^{\circ} \mathrm{C}$ and adhesive strength: $10.0 \mathrm{~N} / \mathrm{mm}^{2}$.

\subsubsection{Specimen preparation}

Prior to adhesion, the contact shoulder and gap surfaces of the joint elements were covered with a general adhesive tape from the packaging industry to prevent adhesive bonding between them in order to examine the strength provided by gluing on the contact surfaces of the joint elements. For the application of the adhesive, two cases were taken into account. In the first case, the tenons to be tested were glued on each side (single-glued joints), while in the other case, the adhesive was applied on the surface of both the mortise and tenon elements (double-glued joints). In all cases, the adhesive was thoroughly spread over the entire surface (refer to Fig. S1 in the Online Resource), and after 1-2 min the mortise and tenon elements were assembled together and finally rested for $12 \mathrm{~h}$. 


\subsection{Methods}

\subsubsection{Production of mortise and tenon elements}

The production of mortise and tenon corner joints was carried out on a GRIGGIO T210 milling machine, which was equipped with changeable milling knives from Leitz Hungaria Tools Ltd., Hungary (refer to Fig. S2 in the Online Resource). The milling knives, with a tolerance of $0.1 \mathrm{~mm}$ from the minimum $8 \mathrm{~mm}$ set point, were purchased from Leitz Hungaria Tools Ltd., Hungary. The dimensions and the number of wooden joints were adjusted to the parameters of the milling tool, raw material and the compression tests to be performed and determined according to Table 1 .

The mortise elements were made by setting the milling tool to zero thickness position while the tenon elements were machined in two milling cutter pairs on one axle. The physical dimensions of the joint elements are shown in Fig. 1. Depending on the machine configuration, the milling tool, the raw material, the technical conditions during production and the handling staff's capabilities, each machining process involved dimensional differences in the produced test specimens (for different joint fits). The thickness of the elements was determined by taking into account the minimum shoulder support width $(\sim 5-6 \mathrm{~mm})$ recommended by professional experience. The mortise and tenon specimens were arranged into units of 30, assembled together, labelled and covered with a protective foil. During all stages of production, the temperature of the chamber was maintained at $22-24{ }^{\circ} \mathrm{C}$ while the humidity was kept at $45-50 \%$.

\subsubsection{Measurement of thickness and gap width of the joint elements}

The mortise and tenon test specimens were sequentially numbered from 1 to 60 for their identification during the measurements. The measurement lines were drawn at

Table 1 Examined specimen dimensions, joint fit categories and number of test specimens

\begin{tabular}{|c|c|c|c|c|c|}
\hline \multirow{2}{*}{$\begin{array}{l}\text { Tenon dimensions } \\
31.3 \times 31.3 \mathrm{~mm}\end{array}$} & \multirow{2}{*}{$\begin{array}{l}\text { Specimen length } \\
250 \mathrm{~mm}\end{array}$} & \multirow{2}{*}{$\begin{array}{l}\text { Specimen thickness } \\
\text { 6-8-6 mm }\end{array}$} & \multirow{2}{*}{$\begin{array}{l}\text { Categories of joint fit } \\
\text { Tight \#1 }(0.2 \mathrm{~mm})\end{array}$} & \multicolumn{2}{|c|}{$\begin{array}{l}\text { Number of test specimens for } \\
\text { compression analysis }\end{array}$} \\
\hline & & & & Tenon & 60/joint fit \\
\hline & & & Tight \#2 (0.1 mm) & Mortise & 60/joint fit \\
\hline & & & Fixed \#3 $(0.0 \mathrm{~mm})$ & & \\
\hline & & & Loose \#4 $(-0.1 \mathrm{~mm})$ & & \\
\hline & & & Loose \#5 (-0.2 mm) & & \\
\hline & & $8-8-8 \mathrm{~mm}$ & Tight \#1 (0.2 mm) & Tenon & 60/joint fit \\
\hline & & & Tight \#2 $(0.1 \mathrm{~mm})$ & Mortise & 60/joint fit \\
\hline & & & Fixed \#3 $(0.0 \mathrm{~mm})$ & & \\
\hline & & & Loose \#4 (-0.1 mm) & & \\
\hline & & & Loose \#5 (-0.2 mm) & & \\
\hline \multirow{2}{*}{\multicolumn{2}{|c|}{ Total number of test specimens examined }} & & & Tenon & 600 \\
\hline & & & & Mortise & 600 \\
\hline
\end{tabular}
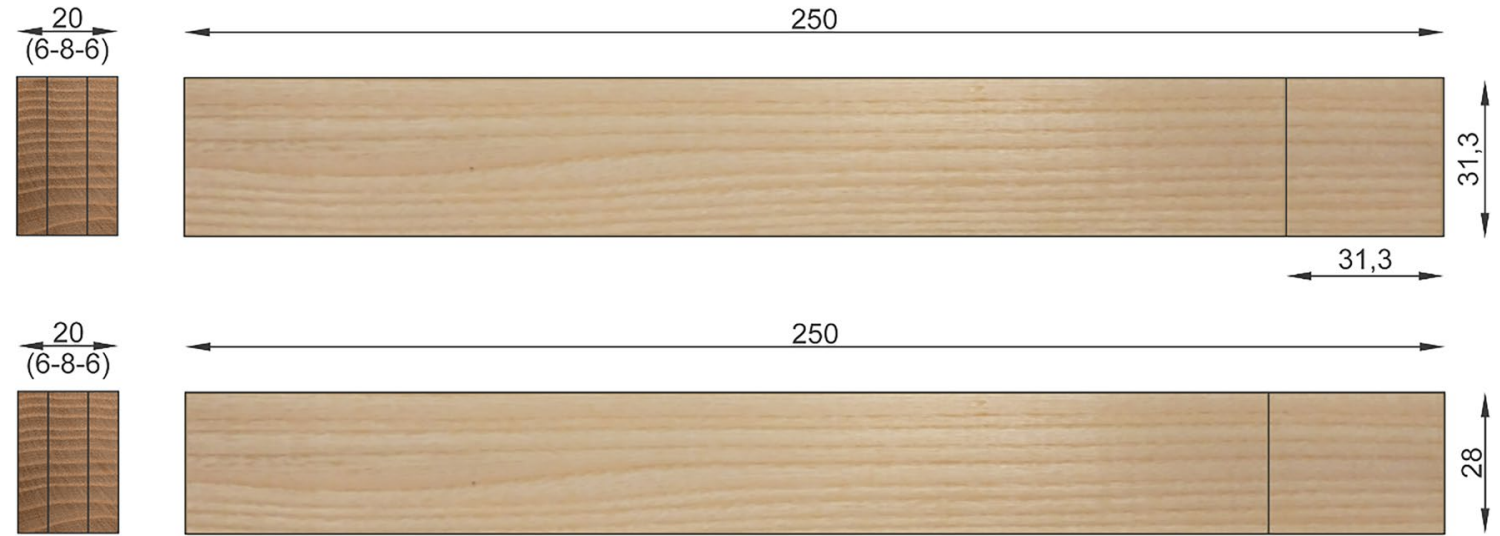

250

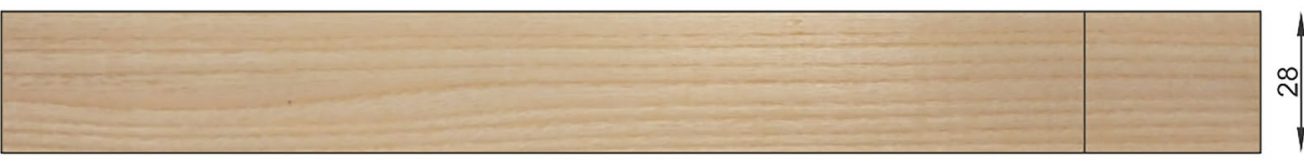

Fig. 1 Dimensions of the test specimen 
a distance of $6 \mathrm{~mm}$ from the base of the test specimens. Finally, taking into account the uncertainties caused by the mechanical impacts during machining (the milling tool's entry and exit positions), the measurement points were marked at locations in the same order and measured using the digital Mitutoyo MDC-25MX standard and IMP-30 MB internal pre-calibrated micrometres of thousandths millimetre accuracy (refer to Fig. S3 in the Online Resource). During the tests, there were no instructions for positioning the measuring instruments and specimens and the testers positioned them at their own discretion. As shown in Fig. 2, each tenon had five points of measurement, while each mortise had four (since measurement at the centre of the gap was not possible).

Measuring the tenon thickness and mortise gap width provided information on the machining, the measuring tools and testers as well as, on how the two elements should be paired for an optimal fit. In this context, four different theoretical variations of the mortise and tenon elements were possible, as shown in Fig. 3. The most ideal case of pairing theoretically was applied based on the measurement data when jointing the two elements. The measurements were slowed down by the fact that only one micrometre was available and that the joint elements had to be wrapped in protective films before and after each measurement. During the tests, all the three testers took measurements in triplicate to measure 1200 specimens (600 mortises and 600 tenons), amounting to a total of 16,200 measurements per tester, which were recorded separately in Excel spreadsheets.

\subsubsection{Statistical analysis}

The number of testers and replicate measurements were determined so that the results could be statistically evaluated to obtain maximum possible information. Each measuring point of each test specimen was measured thrice by three different testers. Since common measurement instructions were not available to the testers, each tester took the measurements using the most practical measuring system and measuring instrument, and later repeated the measurements. The statistical evaluation of the results was done using Statistica software (v. 13.1) and the R \& R analysis was performed for the data measured by the three testers. A percentage tolerance analysis was done, based on the measured values for

Fig. 2 Points of measurement on the tenon (left) and mortise (right) elements
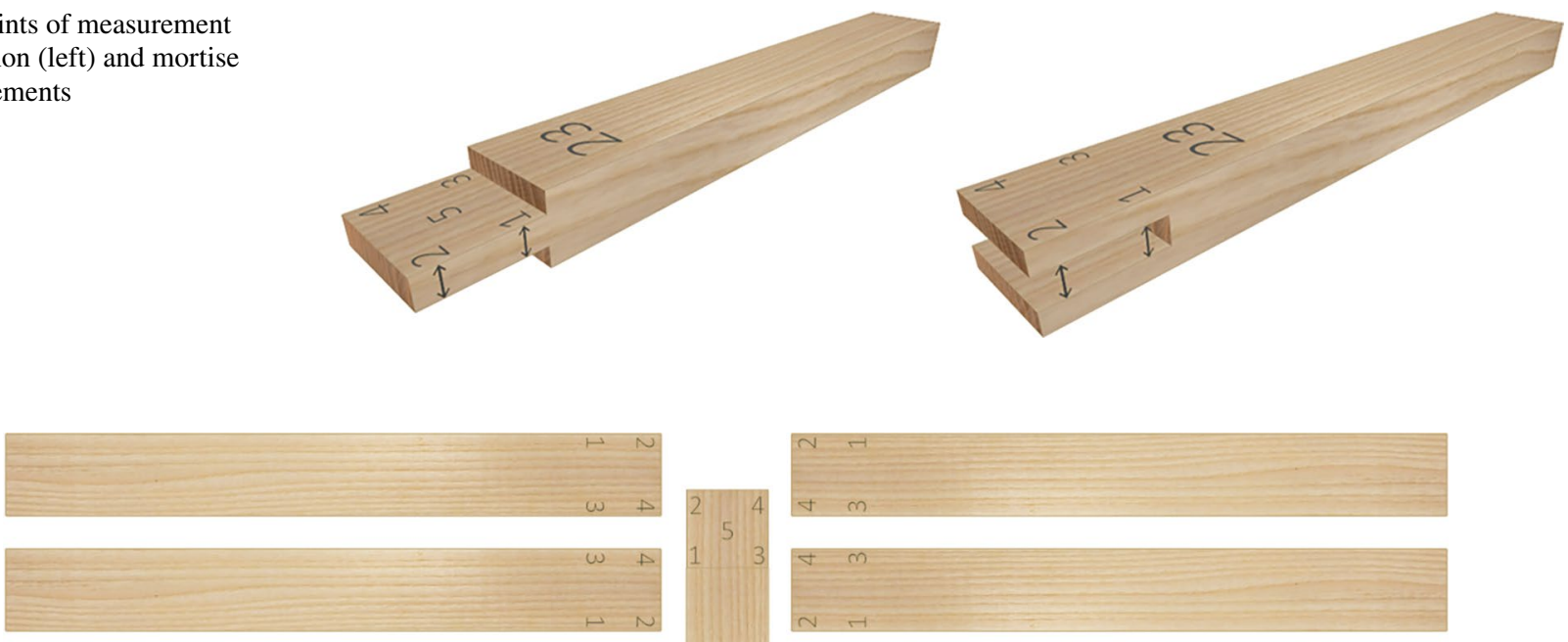

Fig. 3 Possible variations for pairing of mortise and tenon (centre) elements 
each of the three measurements with the following eligibility criteria:

(a) Error $<10 \%$-very good micrometre.

(b) Error between 10 and 30\% - acceptance depends on the context of use.

(c) Error $>30 \%$-it is not advisable to accept it, everything necessary must be followed for correction.

The equations for the curves were determined from Eq. 1,

$f(x)=\frac{1}{\sigma \sqrt{2} \pi} \cdot e^{-\frac{(x-m)^{2}}{2 \sigma^{2}}}$

where, $\sigma$ is the standard deviation and $m$ is the mean value.

The following correlations (Eqs. 2-4) were used to calculate the precision indicators for the percentage of tolerance for the thickness and the gap width data measured by the three testers,

$\%$ E.V. $=100 \times \frac{(\text { E.V. })^{2}}{[(R \& R) \times(\text { Jointfit })]}$

$\% A . V .=100 \times \frac{(A . V .)^{2}}{[(R \& R) \times(\text { Jointfit })]}$

$\% R \& R=(\% E . V)+.(\% A . V$.

where, E.V. is equipment variation/repeatability $(\mathrm{R}), A . V$. is appraiser variation/reproducibility $(\mathrm{R})$ and $R \& R$ is repeatability and reproducibility. For clarity of understanding and considering the realistic scope of the article, only one set of data with its evaluation has been presented on an illustrative basis and discussed herein.

\subsubsection{Compression test}

The static compression tests were performed on an Instron 5566 material tester $(10,000 \mathrm{~N}$ maximum load), which recorded the maximum force and displacement (sag) during the test. The tests were performed on the specimens (described in Sect. 2.1.2) in accordance with the standard MSZ EN 310:1999 "Wood-based plates: determination of bending strength and bending flexibility factor". The load was increased at a constant speed throughout the test and the speed was selected so that the corner joint breaks in $60 \pm 30 \mathrm{~s}$. The machine was fitted with a "V" slot for the test in order to prevent slipping in the plane of adhesion, and the corner joints were inserted as shown in Fig. 4. The applied crushing load from the top of the specimen and the force exerted from the specialized fixtures at the bottom of the Instron tester were along the same vertical axis. The applied loads and the resulting displacements were recorded along this vertical axis.

\section{Results and discussion}

\subsection{Analysis of measurement data}

In this section, tenon of $31.3 \times 31.3 \mathrm{~mm}$ with $20 \mathrm{~mm}$ thickness (6-8-6 divisions) and a $0.1 \mathrm{~mm}$ tight joint fit has been elucidated. The tenon thickness and the mortise gap width values of the manufactured mortise and tenon joints were measured at five and four points, respectively by each of the three testers with micrometre accuracy. There was no difference in the repetition of the measurements and the recording of the corresponding data. In the report, the data and results for the tenon are presented first followed by those for the mortise elements.

The analysis of the measurement data showed the differences in the thickness of the tenon as measured by the three testers due to machining of the tenon elements. It was observed that the thickness of the tenon elements measured at various points of measurement differed from the set nominal value, which implies that the milling operation did not result in completely uniform or parallel surfaces. The average tenon thickness data measured by the testers at each of the five points of measurement are shown in Fig. 5. It can be stated that the testers 1 and 2 measured average tenon thickness values close to each other, whereas the tester 3 measured higher values for each point of measurement. Each tester measured the tenon thickness values for each of the three repetitions with less than $0.035 \mathrm{~mm}$ standard deviation.

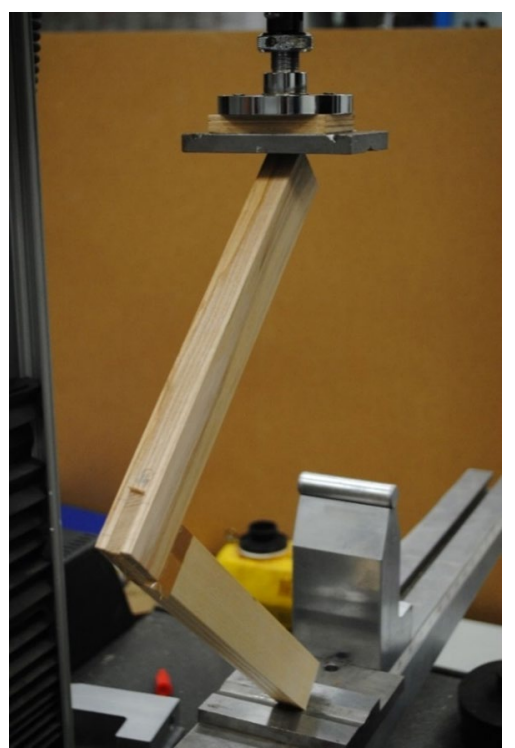

Fig. 4 Compression test on an Instron material tester 
Fig. 5 Average thickness values of the tenon measured by the three testers at each point of measurement for specimens with a $31.3 \times 31.3 \mathrm{~mm}$ tenon and a thickness of $20 \mathrm{~mm}$ (6-8-6 mm divisions)

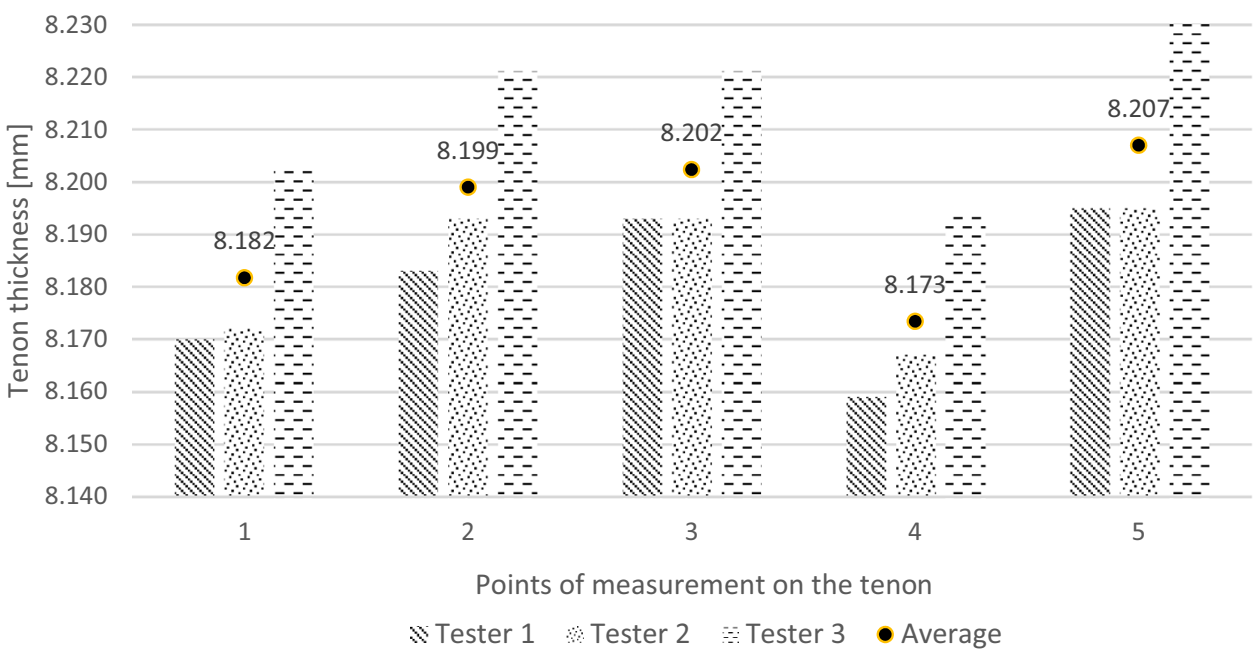

It should be noted that the minimum thickness was obtained at the 4 th point of measurement, where the tool had a constrained movement in the specimen. On the other hand, the $2 \mathrm{nd}$, $3 \mathrm{rd}$ and 5 th points of measurement on the tenon showed more uniform thickness based on the obtained data, which is presumably due to the fact that the constrained movement became less dominant. The second smallest tenon thickness was measured at the 1 st measurement point on the side of the milling tool entering the wood.

On similar lines, analysis of the gap width data measured by the three testers at the different measuring points showed differences in the values due to variation in machining of the mortise elements. It can be stated that in case of mortise specimens, the gap widths measured in accordance with the machining direction consistently recorded, differ from the nominal value. The milling operation did not result in completely uniform or parallel surfaces for the specimens. Here, the deviations of around $0.1-0.2 \mathrm{~mm}$ were obtained at the four points of measurement. The deviations between the extreme values could have been considerably amplified with a less proficient milling machine and tool.

The average gap width data measured by the testers at each of the four points of measurement are shown in Fig. 6. The tester 3 measured the least gap width values for three of the measuring points, similar to those measured in case of tenon elements. In addition, all the three testers measured the gap widths at each measuring point of the mortise within a difference of $0.1 \mathrm{~mm}$. Further, the smallest gap width was obtained for the 2 nd point of measurement that was on the side of the tool entering the specimen. This is due to the fact that at the beginning of the machining, the specimen led to constrained movement of the tool and as the tool left, the constrained movement became less dominant thus leaving a wider gap. It is clear from the data that the 1st, 3rd and 4th points of measurement have more uniform but wider gap widths, which is presumably created by the unconstrained movement of the tool. On comparing the measurement data for the joint elements, it can be stated that the data values of
Fig. 6 Average gap width values of the mortise measured by the three testers at each point of measurement for specimens with a $31.3 \times 31.3 \mathrm{~mm}$ tenon and a thickness of $20 \mathrm{~mm}$ (6-8-6 mm divisions)

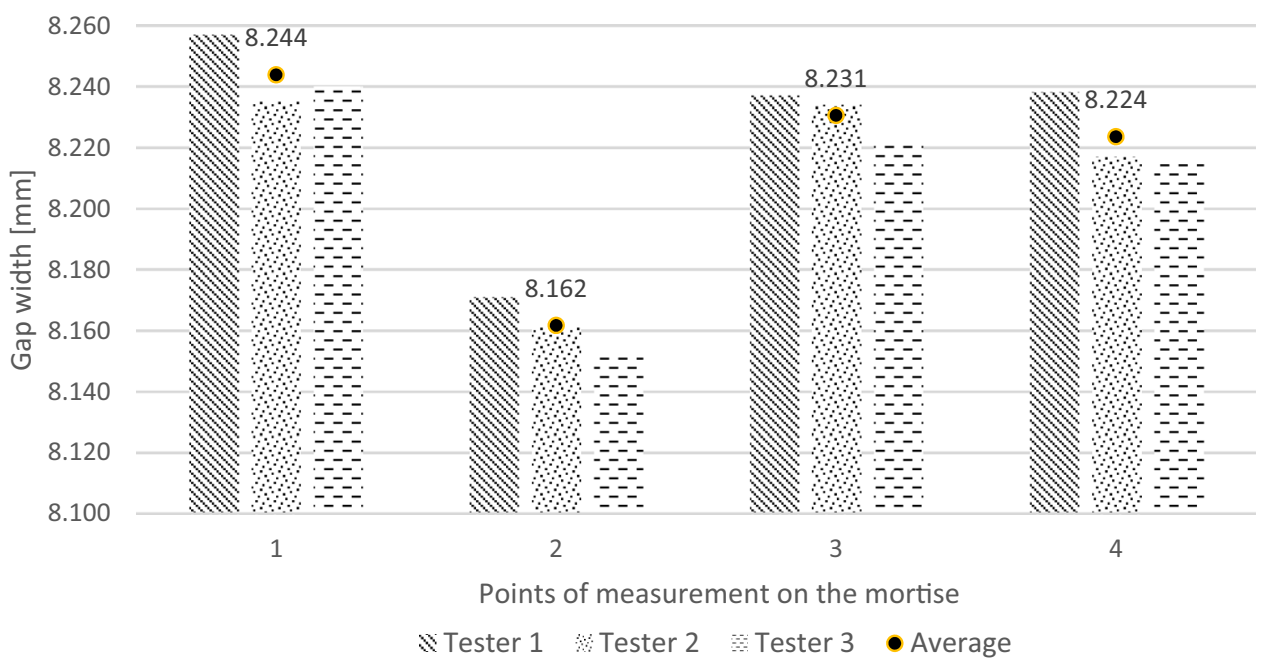


the mortise elements showed greater deviation and uncertainty than those of the tenon elements.

The pairing of the two joint elements is an important feature of a glued structural joint as it has a direct influence on the load bearing capacity. For the different pairing cases, the marking of the pairs in the four measuring locations (e.g. in the first pairing case: $3-1,1-2,4-3,2-4$ ) was such that the first number belonged to the mortise while the second one belonged to the tenon, but always in a way that the numbers corresponding to the tenon were 1-2-3-4. Virtually, the points of measurement on the tenon were made independent of the rotation position of the mortise element. Figure 7 shows the density functions of normal distribution curves of bandwidth $\pm 10 \sigma$ for the first pairing case, determined using Eq. 1.

To make an informed decision on the optimal pairing and bonding of the mortise and tenon elements, the data pairs were examined by a different approach for each tester. The differences in the matching pairs were extracted from the mean of the total sample for that pairing and the lowest value was desired as it would have the least fluctuation around the average. In this approach, the focus was on cases where at least two or three of the data pairs belonging to the four points of measurement were less than a reference value $(0.045 \mathrm{~mm})$ that was determined as a function of the tolerance limit $(0.1 \mathrm{~mm})$. To determine which tester's data was the most relevant for pairing of mortise and tenon elements, the number of pairing variations in element data pairs was compared to the reference value for each of the 60 sample groups examined by each tester. Among all the pairing combinations of all the joint specimens, the first pairing case seemed to be the most ideal case of pairing. Since there were not enough deviations in the measurement data sets of the testers, further statistical analysis was performed to give information on the adequacy of the applied measurement system.

\subsection{Analysis of repeatability and reproducibility (R \& R) test}

The percentage of contribution to the total variation of the influencing factors for the measurement of tenon elements, and the ratio of the repeatability and reproducibility error (calculated using Eqs. 2-4) of the measuring system were examined. For an appropriate measuring system, the degree of variation of the specimen-to-specimen should ideally be greater than $90 \%$. The results obtained (Table 2 and Tables S1-S4 in the Online Resource) for the five points of measurement of the tenon elements unfortunately showed only "50 to 67\%" specimen-to-specimen value, which indicated poor values due to failure in meeting the proposed design criteria. From the results, it can be stated that the degree of specimen-to-specimen variation of the tenon elements is the most favourable at the 1 st point of measurement. This is probably due to the constrained movement of the milling tool in the specimen. This variation is similar in magnitude to that at the 3rd, 4th and 5th point of measurement, and least at the 2nd point of measurement that is located directly next to the milling tool entering the specimen.

The percentage of contribution to the total variation of the influencing factors for the measurement of tolerance of tenon elements, and the ratio of the repeatability and reproducibility error of the measuring system were also examined. For an appropriate measuring system, the degree of tolerance variation of the specimen-to-specimen should ideally be $99 \%$. It can be stated that the optimally expected and foreseen $\pm 0.1 \mathrm{~mm}$ tolerance with the milling machine and tool applied could be maintained at all five points of measurement, and could even be tightened by about $20-25 \%$
Fig. 7 Density functions of the measuring locations for the mortise and tenon specimens, with a thickness of $0.1 \mathrm{~mm}$, for the first pairing case

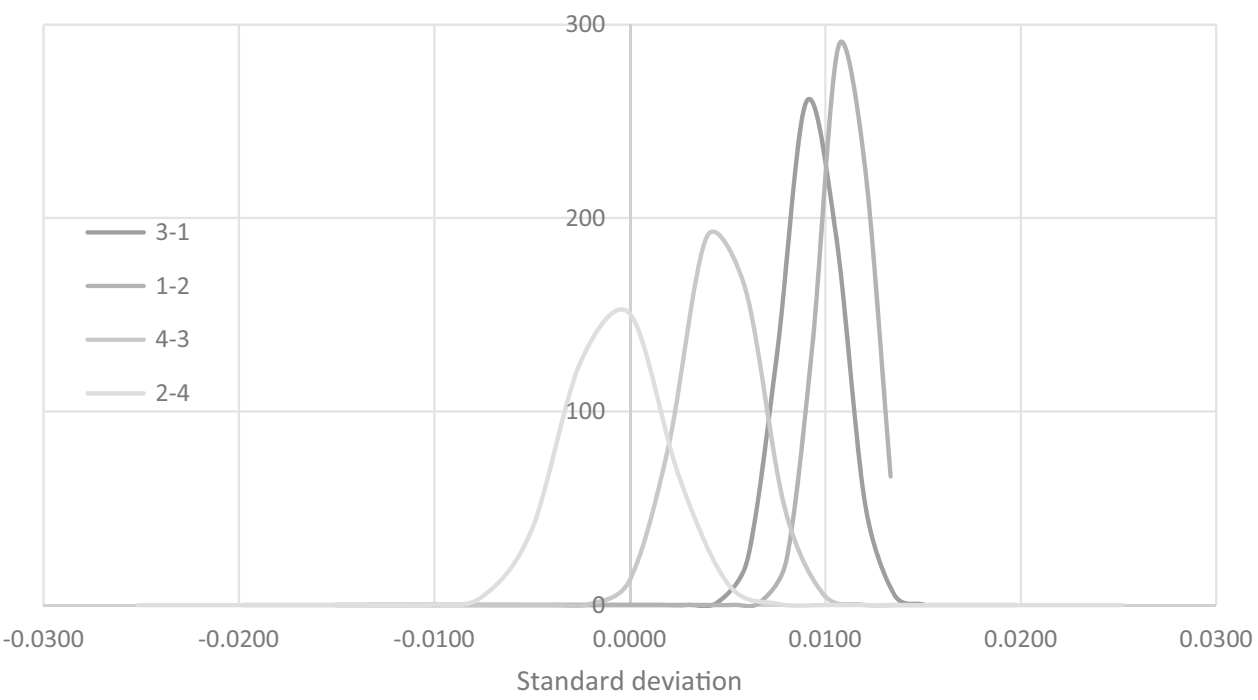


Table $2 \mathrm{R} \& \mathrm{R}$ test of the measured data at the 1 st point of measurement of the tenon elements for all the three testers (specimen-to-specimen variation)

\begin{tabular}{|c|c|c|c|c|}
\hline \multirow[t]{2}{*}{ Source $($ Sigma $=$ R-bar/d2) } & \multicolumn{4}{|c|}{$\begin{array}{l}\text { Variance components: } \text { mean }=8.18182, \mathrm{R}-\mathrm{bar}=0.137 \mathrm{E}-1 \\
\mathrm{R}(\mathrm{xbar})=0.336 \mathrm{E}-1, \mathrm{R}(\text { specimens })=0.129222 \\
\text { Operators: } 3 \text {, specimens: } 60 \text {, trials: } 3\end{array}$} \\
\hline & Estimated sigma & Estimated variance & $\%$ of $\mathrm{R} \& \mathrm{R}$ & $\%$ of total \\
\hline Repeatability & 0.008071 & 0.000065 & 17.4684 & 5.7415 \\
\hline Reproducibility & 0.017544 & 0.000308 & 82.5316 & 27.1265 \\
\hline Specimen-to-specimen & 0.027599 & 0.000762 & & 67.1320 \\
\hline Combined R \& R & 0.019311 & 0.000373 & 100.0000 & 32.8680 \\
\hline Total & 0.033684 & 0.001135 & & 100.0000 \\
\hline
\end{tabular}

(Table 3, and Tables S5-S8 in the Online Resource). The comparison can be seen as a percentage of the total variation, as well as a percentage of the tolerance range. The precision of machining, that is, the minimum tolerability is typical of the 'element variation' line.

The values of the thickness measurement data for the 60 tenon elements measured at different points by the three testers in triplicate are depicted in Fig. 8 (refer to Fig. S4-S7 in the Online Resource). It can be stated that the testers 1 and 2 measured approximately the same average at wider ranges of fluctuations. On the other hand, tester 3 measured at a higher average value but at a much narrower range of fluctuations for each point of measurement, which could be due to the individual use of the micrometre. Despite the large number of measurements (540 measurements per tester), only a few cases showed outbound values resulting from a misalignment of the micrometre. Extreme values that were present at the same specimen measured by all three testers may be due to the machining errors.

After analysing the measurement data for the tenon elements, the data for the mortise elements were analysed to determine the percentage of contribution to the total variation of the influencing factors and the ratio of repeatability and reproducibility errors of the measuring system. The results obtained (Table 4, and Tables S9-S11 in the Online Resource) for the four points of measurement of the mortise elements show better results than those of the tenon elements, but are still underestimated. In case of mortise elements, the degree of specimen-to-specimen variation of about $67 \%$ was obtained for the 1 st and 2 nd point of measurement, while the degree of variation of $85 \%$ was obtained for the $3 \mathrm{rd}$ and 4 th point of measurement due to constrained movement of the milling tool in the specimen.

Similarly, the percentage of contribution to the total variation of the influencing factors for the measurement of tolerance of the mortise elements (Table 5, and Tables S12-S14 in the Online Resource) was analysed. It can be stated that the optimally expected and foreseen $\pm 0.1 \mathrm{~mm}$ tolerance with the milling machine and tool applied could be maintained for all the four points of measurement, and based on the results obtained at the 1st and 2nd point of measurement, it could be even tightened in this case, the 4 th point of measurement was expected to exceed the target value.

The values of the gap width measurement data for the 60 mortise elements measured at different points by the three testers in triplicate are depicted in Fig. 9 (Fig. S8-S10 in the Online Resource). It can be stated that tester 3 measured the least fluctuation and the lowest mean, which was also attributable to the individual use of the micrometre. In spite of the large number of measurements, a few outliers originating from machining errors could be seen in some cases.

Table $3 \mathrm{R} \& \mathrm{R}$ test of the measured data at the 1st point of measurement of the tenon elements for all the three testers (given acceptable tolerance)

Source (pooled standard deviation) $\quad$ Percent tolerance analysis: mean $=8.18182$, standard deviation $=0.342 \mathrm{E}-1$ Operators: 3 , specimens: 60 , trials: 3

\begin{tabular}{llrrr} 
& Measurement units & \% Process variation & \% Total contribution & \% Tolerence \\
\hline Repeatability (equipment variation) & 0.041926 & 22.9447 & 5.2646 & 20.9628 \\
Reproducibility (appraiser variation) & 0.096359 & 52.7347 & 27.8095 & 48.1797 \\
Specimen variation & 0.149484 & 81.8083 & 66.9259 & 74.7421 \\
Combined R \& R & 0.105085 & 57.5101 & 33.0741 & 52.5426 \\
Total process variation & 0.182725 & 100.0000 & 100.0000 & 91.3625 \\
Tolerance & 0.200000 & & 100.0000
\end{tabular}


Fig. 8 Graphical representation of the measured data at the $1 \mathrm{st}$ point of measurement of the tenon elements with respect to each of the three testers
Table 4 R \& R test of the measured data at the 1 st point of measurement of the mortise elements for all the three testers (specimen-to-specimen variation)
Repeatability \& Reproducibility Summary Plot

No. of Operators: 3

No. of Parts: 60

No. of Trials: 3

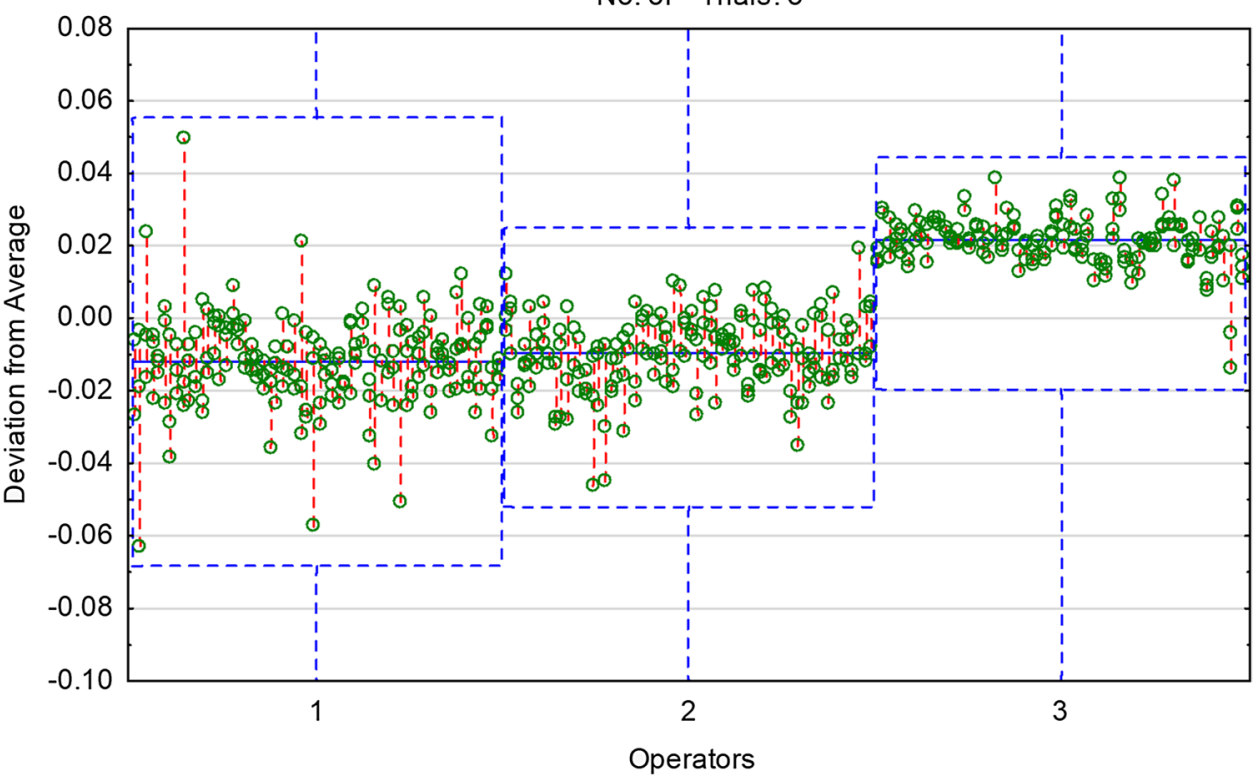

Table $5 \mathrm{R} \& \mathrm{R}$ test of the measured data at the $1^{\text {st }}$ point of measurement of the mortise elements for all the three testers (given acceptable tolerance)

\begin{tabular}{|c|c|c|c|c|}
\hline \multirow[t]{2}{*}{ Source (pooled standard deviation) } & \multicolumn{4}{|c|}{$\begin{array}{l}\text { Percent tolerance analysis: } \text { mean }=8.24413 \text {, standard deviation }=0.439 \mathrm{E}-1 \\
\text { Operators: } 3 \text {, specimens: } 60 \text {, trials: } 3\end{array}$} \\
\hline & Measurement units & $\%$ Process variation & $\%$ Total contribution & $\%$ Tolerence \\
\hline Repeatability (equipment variation) & 0.079401 & 50.4850 & 25.4874 & 39.7006 \\
\hline Reproducibility (appraiser variation) & 0.058702 & 37.3240 & 13.9308 & 29.3510 \\
\hline Specimen variation & 0.122415 & 77.8343 & 60.5818 & 61.2076 \\
\hline Combined R \& R & 0.098744 & 62.7839 & 39.4182 & 49.3722 \\
\hline Total process variation & 0.157277 & 100.0000 & 100.0000 & 78.6383 \\
\hline Tolerance & 0.200000 & & & 100.0000 \\
\hline
\end{tabular}

\subsection{Analysis of compression test}

As a proof for validation of the $\mathrm{R} \& \mathrm{R}$ test for optimal jointpairing, the compression test measurements were taken on the glued mortise and tenon elements. For each of the five joint fit categories, the data measured by the three testers were taken into account when pairing the joint elements. The failure of the investigated bonds was found to 
Fig. 9 Graphical representation of the measured data at the $1 \mathrm{st}$ point of measurement of the mortise elements with respect to each of the three testers
Repeatability \& Reproducibility Summary Plot
No. of Operators: 3
No. of Parts: 60
No. of Trials: 3

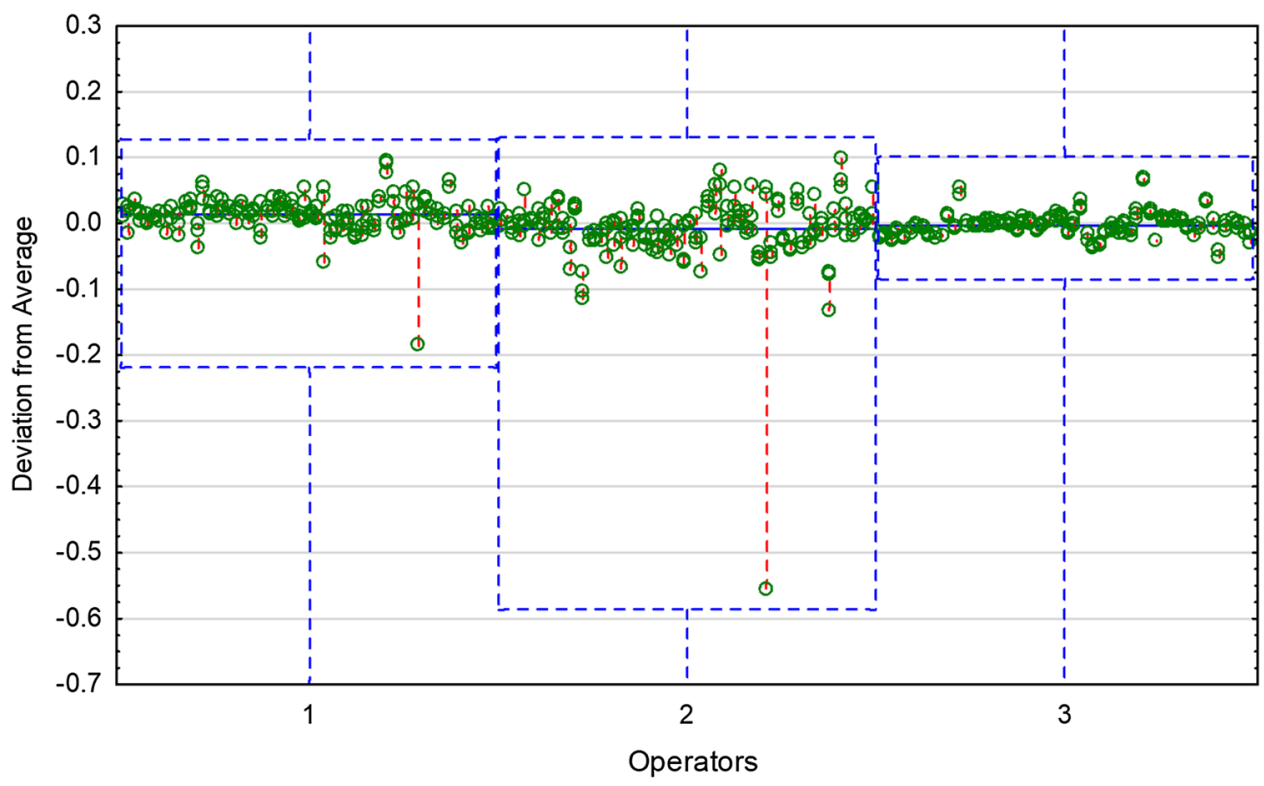

be fundamentally twofold. In case of double-glued joints, wherein the surfaces of both the mortise and tenon elements were glued and bonded with adhesive, the failure occurred due to the breaking of the tenon (refer to Fig. S11 in the Online Resource). This indicates that the bonded surface had a load capacity greater than the specimen compressive strength of the given thickness. However, in case of single-glued joints, where only the surfaces of the tenon were glued, elongation along the glued surface was observed (refer to Fig. S12 in the Online Resource).

The Instron material tester graphically recorded the failure process for each of the joints, as shown in Fig. 10. It can clearly be seen how the increasing elastic deformation phase approaches the failure of the joint, which is different from the linear phase. Subsequently, the curve begins to flatten and reaches the maximum, before a smaller reduction, the force drops thus indicating the failure of the material being tested.

The maximum breaking force and displacement results of the compression test of the $0.1 \mathrm{~mm}$ joint fit for single-glued joints are graphically illustrated in Fig. 11, whereas those for double-glued joints are shown in Fig. 12. It is obvious that higher breaking force and displacement values were obtained on an average for double-glued joints. There was no clear connection between the maximum breaking force and the displacement values of the individually measured double-glued joints, which could be primarily due to the anatomical differences in the specimens. Regardless of this, a trend is observed in the fracture and displacement values

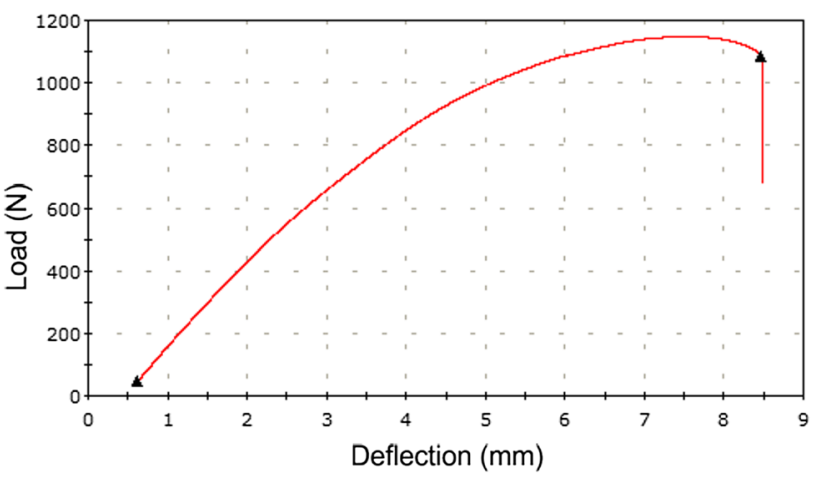

Fig. 10 Force-deflection diagram recorded by the Instron material tester

of the tested specimens. In the case of double-glued joints, an average of $17.6 \%(180 \mathrm{~N})$ higher breaking force was obtained as compared to the single-glued joints. The displacements averaged $24 \%(1.6 \mathrm{~mm})$ higher until the point of failure for the double-glued joints. The maximum breaking force was $1210 \mathrm{~N}$ and the maximum displacement was found to be $9.5 \mathrm{~mm}$ in the latter case.

Each of the joint fit categories were examined in a similar way. However, considering the realistic scope of the manuscript, only data for the $0.1 \mathrm{~mm}$ joint fit have been elaborated above. Figure 13 shows the average of maximum breaking force versus displacement values for the five joint fit categories tested for the single-glued joints. 
Fig. 11 Breaking force versus displacement for joint fit of $0.1 \mathrm{~mm}$ for single-glued joints
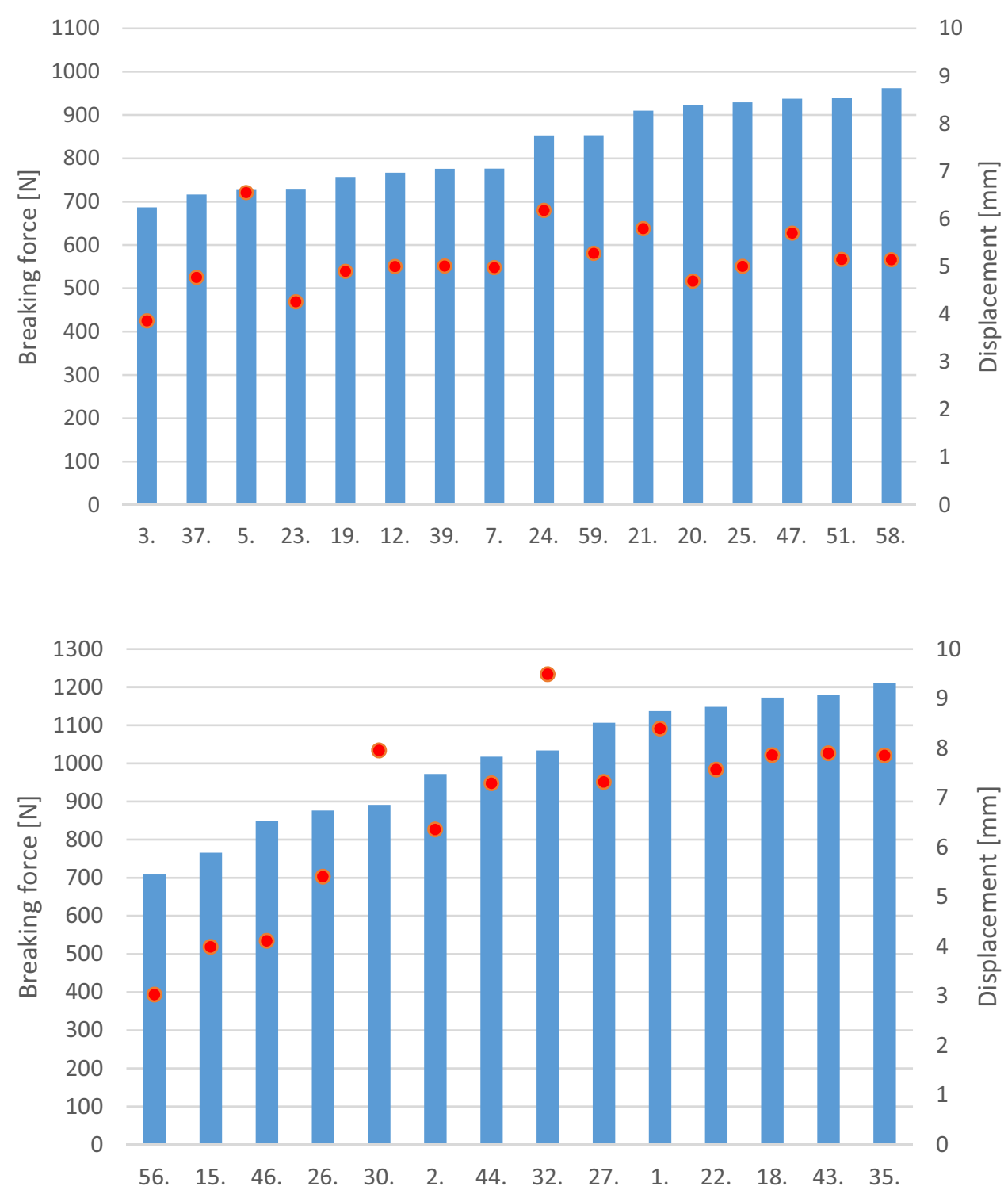

Fig. 12 Breaking force versus displacement for joint fit of $0.1 \mathrm{~mm}$ for double-glued joints

$\xi$ 
Fig. 13 Average breaking force and displacement values for the five joint fit categories in singleglued joints
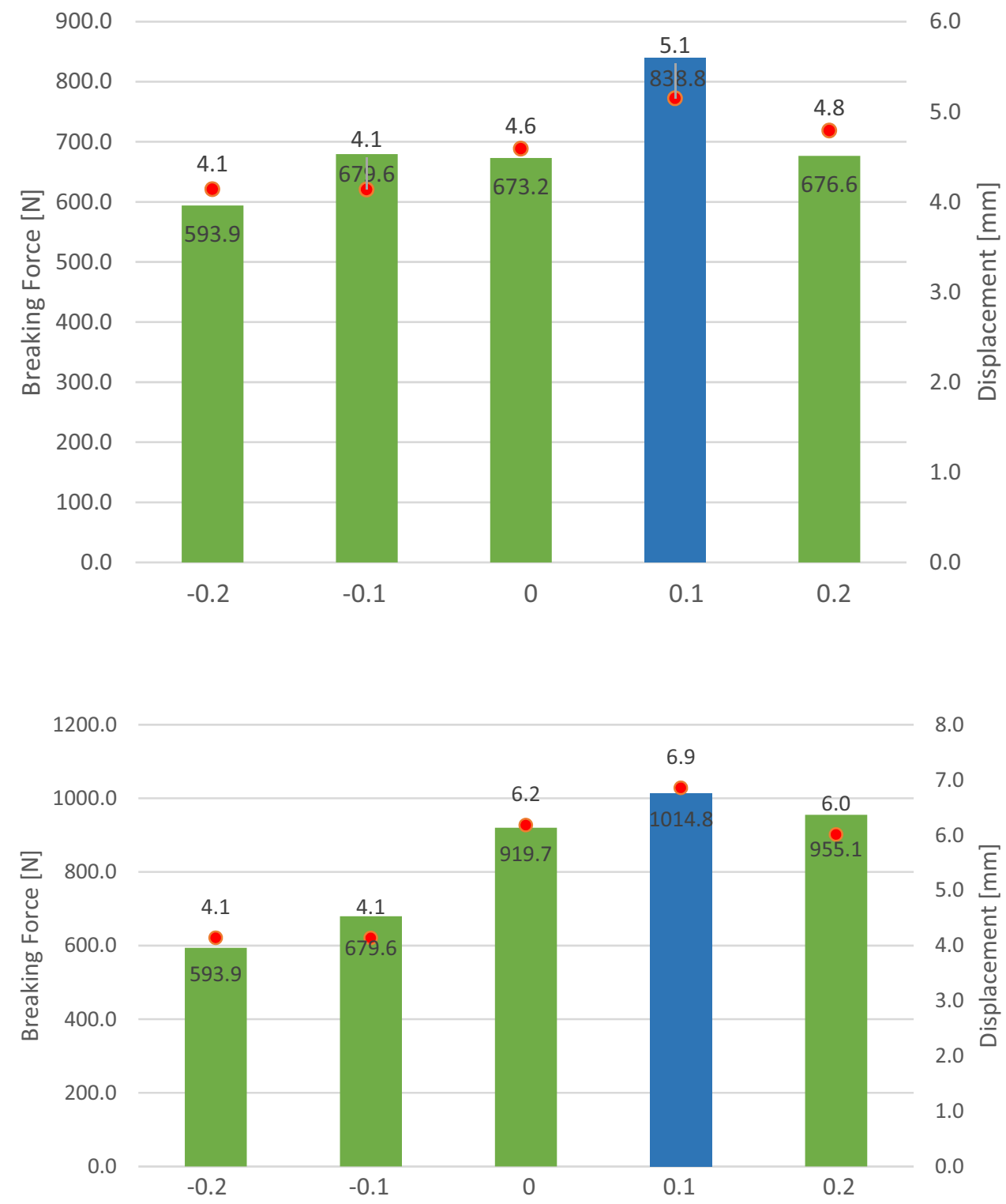

Fig. 14 Average breaking force versus displacement values for the five joint fit categories in double-glued joints glued surfaces but simply the tenons were broken, which indicated the point of failure of ash wood. Further, the compressive strength of the produced joint elements was determined taking into account the cross-sectional dimensions and other geometric dimensions of the examined joints (refer to Fig. S13 in the Online Resource for illustration). In this context, substituting the average breaking force and the actual geometric dimensions, a compressive strength of $117.12 \mathrm{MPa}$ was obtained that exceeded the literature value (of around 103-105 $\mathrm{MPa}$ for ash). If the geometrical dimensions (especially the thickness of the tenon) were increased, the magnitude of the compressive strength could also be increased.

\section{Conclusion}

The optimal fitting for pairing of open full-width mortise and tenon joint elements produced from ash wood were investigated using statistical analysis for their effect on the compressive strength of the joint. The characteristics of the measuring instrument should be thoroughly understood in order to ensure the suitability of the measuring system for the measurements. The thickness of the mortise and tenon corner joints produced by milling, could be best characterized by measuring the data at the centre of the tenon. The gap width of the mortise could be best characterized by measuring the data on the side of the tool leaving the wooden specimen. Despite the huge number of test specimens and measurements, the set joint fit 
categories could be maintained with the milling machine and tools, barring a few exceptions. The mortise and tenon joints were found to be the strongest at $0.1 \mathrm{~mm}$ joint fit category among the various joint fit categories tested. The double-glued joints showed higher breaking force (17.6\%) and displacement (24\%) values as compared to the singleglued joints.

Acknowledgements Open access funding provided byUniversity of Sopron (SOE). The authors are grateful to the engineering studentsRéka Horváth and Ádám Kungl for their intense cooperation in the measurements. This article was also made in the frame of EFOP3.6.1-16-2016-00018- "Improving the role of research + development + innovation in the higher education through institutional developments assisting intelligent specialization in Sopron and Szombathely" as well as supported by the UNKP-17-4 "New National Excellence Program of the ministry of human capacities". Their financial support is deeply appreciated.

\section{Compliance with ethical standards}

Conflict of interest The authors declare that they have no conflict of interest.

Open Access This article is licensed under a Creative Commons Attribution 4.0 International License, which permits use, sharing, adaptation, distribution and reproduction in any medium or format, as long as you give appropriate credit to the original author(s) and the source, provide a link to the Creative Commons licence, and indicate if changes were made. The images or other third party material in this article are included in the article's Creative Commons licence, unless indicated otherwise in a credit line to the material. If material is not included in the article's Creative Commons licence and your intended use is not permitted by statutory regulation or exceeds the permitted use, you will need to obtain permission directly from the copyright holder. To view a copy of this licence, visit http://creativecommons.org/licenses/by/4.0/.

\section{References}

Altun S, Burdurlu E, Kılıç M (2010) Effect of adhesive type on the bending moment capacity of miter frame corner joints. BioResources 5:1473-1483. https://doi.org/10.15376/biore s.5.3.1473-1483

Eckelman CA (2003) Textbook of product engineering and strength design of furniture. Purdue University Press, West Lafayette, Indiana
Eckelman CA, Suddarth SK (1969) Analysis and design of furniture frames. Wood Sci Technol 3:239-255

Erdil YZ, Kasal A, Eckelman CA (2005) Bending moment capacity of rectangular mortise and tenon furniture joints. Forest Prod J 55:209-213

Hajdarević S, Martinović S (2014) Effect of tenon length on flexibility of mortise and tenon joint. Procedia Eng 69:678-685. https://doi. org/10.1016/j.proeng.2014.03.042

Imirzi HÖ, Smardzewski J, Döngel N (2015) Method for substitute modulus determination of furniture frame construction joints. Turk J Agric For 39:775-785. https://doi.org/10.3906/tar-1406-92

Jivkov V, Marinova A (2006) Ultimate bending strength and stiffness under compression test of end corner miter joints constructed of solid wood. In: Paper presented at the International Symposium: "Furniture". Technical University in Zvolen, pp 1-7. ISBN 80-228-1577-2

Kasal A, Smardzewski J, Kuşkun T, Erdil YZ (2016) Numerical analyses of various sizes of mortise and tenon furniture joints. BioResources 11:6836-6853. https://doi.org/10.15376/biore s.11.3.6836-6853

Kovacs Z (2017) Enhancement of the machining of solid wood parts for upholstered furniture. In: Paper presented at the 6th International joint conference on environmental and light industry technologies, Budapest, Hungary, 23-24 Nov 2017

Merk V, Chanana M, Gierlinger N, Hirt AM, Burgert I (2014) Hybrid wood materials with magnetic anisotropy dictated by the hierarchical cell structure. ACS Appl Mater Interfaces 6:9760-9767. https://doi.org/10.1021/am5021793

Prekrat S, Smardzewski J (2010) Effect of glueline shape on strength of mortise and tenon joint. Drvna Ind 61:223-228

Ramage MH, Burridge H, Busse-Wicher M et al (2017) The wood from the trees: the use of timber in construction. Renew Sustain Energy Rev 68:333-359. https://doi.org/10.1016/j.rser.2016.09.107

Ratnasingam J, Ioras F (2013) Effect of adhesive type and glue-line thickness on the fatigue strength of mortise and tenon furniture joints. Eur J Wood Prod 71:819-821. https://doi.org/10.1007/ s00107-013-0724-1

Ratnasingam J, Ioras F, McNulty T (2010) Fatigue strength of mortise and tenon furniture joints made from oil palm lumber and some Malaysian timbers. J Appl Sci (Faisalabad) 10:2869-2874. https ://doi.org/10.3923/jas.2010.2869.2874

Tankut AN, Tankut N (2011) Section modulus of corner joints in furniture frames as engineering design criteria for their efficient construction. Mater Design 32:2391-2395. https://doi.org/10.1016/j. matdes.2010.10.027

Viswanathan M (2005) Measurement error and research design. Sage Publications, p 433. ISBN 1-4129-0642-3

Wilczyński A, Warmbier K (2003) Effect of joint dimensions on strength and stiffness of tenon joints. Folia For Pol 34:53-66 